\title{
Building a construction procurement negotiation training game model: Learning experiences and outcomes
}

\section{Ren-Jye Dzeng, Ken-Yu Lin and Pei-Ru Wang}

Ren-Jye Dzeng is a professor of Civil Engineering and former dean of General Affairs at National Chiao-Tung University, Taiwan. He holds a PhD from the University of Michigan, Ann Arbor, USA. Ken-Yu Lin is an assistant professor from the Department of Construction Management at the University of Washington and the former Education Committee Chair for the Technical Council on Computing and Information Technology, American Society of Civil Engineers. Dr. Lin holds a PhD from the University of Illinois, Urbana-Champaign. Pei-Ru Wang is a PhD candidate in Civil Engineering at National Chiao-Tung University, Taiwan. She works at the Construction and Disaster Prevention Research Center of Feng Chia University. Address for correspondence: Dr Ren-Jye Dzeng, Professor of Civil Engineering at National Chiao-Tung University, No. 1001, Ta Hsueh Road, Hsinchu 300, Taiwan. Email: rjdzeng@mail.nctu.edu.tw

\begin{abstract}
Game-based education is a promising method for encouraging student learning. Although learning construction procurement and negotiation require hands-on practice, in most construction management courses at the college level, this subject is taught by using lectures and case studies. In this study, a construction procurement and negotiation game was developed, and paper-based and web-based versions were implemented. The game enables students to play the role of contractors or suppliers and generate profits by negotiating and procuring or selling reinforcing steel in a simulated market with a probabilistic nature. The experimental results indicate that playing both versions of the game increased student learning motivation, satisfaction and outcomes. Students awarded the web-based game higher assessment scores than they did for the paper-based game. Students playing either version of the game also achieved higher test scores than students who were taught using the traditional approach did. However, for students with work experience, playing the paper-based game resulted in higher scores than the web-based game scores.
\end{abstract}

\section{Introduction}

Procurement negotiation in construction management $(\mathrm{CM})$ depends heavily on experience. Erdem (2009) stated that case-based teaching and learning are crucial for teaching procurement negotiation to students. Most university CM courses primarily consist of lectures that do not provide students with hands-on decision-making experience in applying newly gained knowledge. Also, most CM graduates do not gain practical experience or any relevant skills until they enter the field. This discrepancy between theoretical and practical negotiation training suggests that current higher education practices are inadequate.

Researchers have developed simulation-based games for construction fields, including bidding, equipment management, activity operation and resource allocation. However, only the Negotiation Game created by Dudziak and Hendrickson (1988) focuses on construction negotiation. In practice, a project that involves material procurement requires a contractor to evaluate multiple prospective suppliers in a competitive market simultaneously. From this perspective, the 


\section{Practitioner Notes}

What is already known about this topic

- Educational games are a crucial instructional strategy for promoting student learning motivation.

- Although learning construction procurement and negotiation requires hands-on practice, in most college CM courses, students are taught by using lectures and case studies.

What this paper adds

- In this study, a game that provides students with hands-on experience with construction procurement and negotiation was developed. Students act as contractors or suppliers in a simulated market with a probabilistic nature.

- This study implements paper-based and web-based versions of the game.

- In this study, the test scores and results of learning motivation, satisfaction and effectiveness surveys of students participating in the traditional approach combined with the paper-based and web-based games were compared.

Implications for practice and/or policy

- Both versions of the proposed game increased student test scores, learning motivation, satisfaction and effectiveness more than the traditional approach did. Therefore, the game should be included in related CM courses.

- The web-based game produced higher assessment scores than the paper-based game did, indicating that computerisation benefits procurement and negotiation games, which require meticulous calculations and bookkeeping skills.

- Students with work experience achieved higher scores when playing the paper-based game than when playing the web-based game. This implies that the web-based game is not always superior to the paper-based game, especially for students working in the construction industry who may have less experience using computers.

Negotiation Game, which allows only one-to-one negotiation, is inadequate. In addition, playing the Negotiation Game requires players (ie, students) to be honest. Therefore, the game is unsuitable for several players, such as an entire class, when used as a teaching supplement.

In this study, a game was developed to provide students with hands-on practice with CM procurement negotiation to complement the traditional teaching approach and thereby improve the knowledge of students, thus enabling them to meet industry requirements. In the game, students are divided into two groups to play the roles of contractors and suppliers. The game simulates the decision-making scenario when an appropriate amount of reinforcing steel must be procured on suitable negotiable terms to fulfil contracted project requirements. The model incorporates essential factors that influence procurement decisions, such as uncertainty about supplier delivery schedules and work quality, the independent choice of suppliers with whom to negotiate, and simultaneous negotiation with multiple suppliers. In addition, it uses anonymous communication to prevent cheating. In this study, paper-based and web-based versions of the game were implemented.

Another aim of this study was to answer the following questions by creating a true experiment to compare the traditional, and paper-based and web-based game approaches. 
1. Which teaching approach results in higher test scores?

2. Compared with the traditional approach, does the paper-based game significantly improve student learning motivation, satisfaction and effectiveness?

3. Compared to the traditional approach, does the web-based game significantly improve student learning motivation, satisfaction and effectiveness?

\section{Literature review}

Numerous researchers (Fasli \& Michalakopoulos, 2006; Shaffer, Squire, Halverson \& Gee, 2008) have described the advantages of learning from educational games. Games encourage active learning and motivate participation and persistence. Furthermore, games provide an instant feedback on user actions. In certain fields, games may be the only possible means of simulating and solving real problems. For example, simulations have been used to teach pilots (Stottler \& Vinkavich, 2000). Several studies have concluded that games positively affect problem solving, achievement, and interest and engagement in task learning (Kim, Park \& Baek, 2009; Tüzün, Yılmaz-Soylu, Karakus, Inal \& Kızılkaya, 2009).

Studies have also investigated the learning effects of applying computer games to in-class teaching. For example, Van Eck and Dempsey (2002) used a computer simulation game in a mathematics course and discovered that students produced exceptional learning achievements in non-competitive settings. Kim et al (2009) demonstrated that children developed high-level cognitive competencies by interacting with their peers through educational computer games, indicating that such games could help students improve their learning performance. Cagiltay (2007) indicated that educational computer games provide a more interesting learning environment for acquiring knowledge compared with traditional teaching methods. Several studies have also reported that educational computer games can enhance student learning motivation (Huang, Huang \& Tschopp, 2010; Papastergiou, 2009). For example, Ke (2008) indicated that educational computer games are significantly more effective in promoting learning motivation than are traditional paper-and-pencil drills.

In the past decade, numerous educational computer games have been developed for various applications, including civil engineering courses (Ebner \& Holzinger, 2007), computer courses (Connolly, Stansfield \& Hainey, 2007; Wang \& Chen, 2010), geography courses (Tüzün et al, 2009), language courses (Hao et al, 2010; Liu \& Chu, 2010), management courses (Chang, Peng \& Chao, 2010; Kiili, 2007) and nutrition courses (Yien, Hung, Hwang \& Lin, 2011). Researchers have developed simulation-based games for construction fields such as bidding, equipment management, activity operation and resource allocation, for example, Super-Bid (AbouRizk, 1992), Equipment Replacement Game (Nassar, 2002), CONSTRUCTO (Halpin \& Woodhead, 1973), Negotiation Game (Dudziak \& Hendrickson, 1988), Parade of Trade (Tommelein, Riley \& Howell, 1999) and LEAPCON (Sacks, Esquenazi \& Goldin, 2007).

However, although various games have been developed for the construction domain, only the Negotiation Game (Dudziak \& Hendrickson, 1988) focuses on construction negotiation. The game simulates a contract negotiation between a gas company and a design or building firm and applies a scoring system that evaluates how effectively the final agreement fulfils the desires of each party. The negotiation involves two parties with multiple issues (eg, duration, late completion penalties, bonuses, report format and frequency of progress reports) to be resolved. The gameplaying experience demonstrated that most agreements were not Pareto optimal, with an approximately $10 \%$ potential improvement. This corresponds to findings derived from the negotiator-expert system developed by Dzeng and Lin (2004). They discovered that the optimal agreement is based on the utility preferences of negotiating parties. Practically, when a project requires material procurement, a contractor must simultaneously evaluate multiple prospective suppliers in a competitive market. Therefore, the Negotiation Game, which allows only one-to-one negotiation, is inadequate. 
In addition, playing the Negotiation Game requires players (ie, students) to be honest. Therefore, the game is unsuitable for several players, such as an entire class, when used as a teaching supplement.

The concept of learning by doing argues that students typically learn effectively through hands-on experience. Therefore, to provide students with negotiation experience in a realistic and dynamic environment, we developed a game that enables students in a virtual competitive market to act as contractors or suppliers, evaluate and select multiple prospective suppliers for negotiation, negotiate on several terms, address the uncertainty of hired supplier performance, manage cash flow, and handle dynamic issues, such as the trade-off between low procurement costs and high storage costs for large procurements.

To evaluate the performance of an educational game, researchers have developed measurement indicators, including learning motivation (Brown \& Duguid, 1993; Hsieh, Wang, Su \& Lee, 2012; McKeachie, Printrich, Lin \& Smith, 1987; Wigfield \& Eccles, 2000) and satisfaction indicators (Alavi, Yoo \& Vogel, 1997; Chu, Hwang, Tsai \& Tseng, 2010; Piccoli, Ahmad \& Ives, 2001). Several researchers, such as Piccoli et al (2001) and Chou and Liu (2005), have demonstrated that pre- and post-course tests as well as midterm and final grades are suitable for measuring learning effectiveness. Chu et al (2010) also developed survey indicators for measuring learning effectiveness.

Procurement negotiation issues in the construction industry

Procurement negotiation in the construction industry can be viewed as the process of reaching an agreement in a multidimensional space. Each dimension corresponds to a negotiable issue, which can be discrete or real valued, and each issue may have several options. Dzeng and Lin (2004) conducted a survey to identify key negotiable issues that may arise during construction material procurement negotiations. They also studied common options used for addressing each issue, and contractor and supplier preferences regarding these options. Key issues identified included the price; payment terms; payment period; advance payments; resource provision; freightage; delivery; and opportunities for extended procurement, mass procurement and future procurement (Dzeng \& Lin, 2005).

These issues can be classified into four categories according to the range of available options. The first category is price, and its options lie on a continuous spectrum. The second category includes issues that have a limited number of commonly used options. For example, payment term options include cash, 30-day checks, 45-day checks and 60-day checks. The third category includes issues with a list of items and quantities as the options. For example, resource provision options are a list of provided resources and quantities. The fourth category includes issues with quantityrelated options. For example, options for mass procurement opportunities are the maximal procurable quantities. For simplicity, among the issues identified, the proposed game considered only the first and second categories to be negotiable. Issues from the third and fourth categories were ignored because they mainly arise in a negotiation because of contractor capacity flexibility and are wholly determined by contractors. For example, a contractor offers an opportunity for extended procurement to a supplier only when the extended procurement has not been tendered. It is uncommon for a supplier to force a contractor to concede to new procurement during a negotiation. Therefore, these issues were considered as non-negotiable and were determined solely by contractors.

\section{Developing the game}

This study defines the traditional teaching of construction procurement negotiation as a process including lectures on basic procurement and negotiation knowledge and strategies. During this process, students are asked to produce team reports and presentations on related subjects. The 
proposed game-based teaching is defined as a process that includes the same lectures as those used in traditional teaching, but the students play paper-based or web-based games instead of producing reports and presentations.

Game problem

We designed the game to maintain a balance between simplicity and realism. To enable the game to be reused, we modularised the problem, making it flexible and easy to change. Each problem consists of two to five projects, each of which require a certain amount of reinforcing steel (recommended amount ranging from 500 to 3000 tons) to be procured, with an even number of seasons ranging from two to 12 seasons. Each contractor player evaluates and negotiates with prospective suppliers on the market and attempts to complete the projects by procuring the required amount of reinforcing steel before each project is half complete to earn a project completion bonus. Insufficient procurement causes delays, over procurement requires additional storage, insufficient cash flow incurs interest charges and negotiation incurs transportation costs and employee time. These are subject to cash penalties. Selecting a supplier who produces lowquality work or cannot deliver on time is also subject to a penalty. The remaining reinforcing steel can be re-sold to the wholesaler at a discounted market price.

Players may play as contractors or suppliers. The objective of a contractor is to meet the procurement requirements of the projects by acquiring minimal penalty costs and maximal profit. The objective of a supplier is to earn maximal profit by buying from wholesalers at low prices and selling to contractors at high prices in a competitive market. The amount of reinforcing steel owned by the wholesaler, which equals the amount released to the market on which suppliers bid competitively, should be determined by the total amount of reinforcing steel required for the announced projects and the number of contractors in the market. In addition, the game incorporates the uncertain nature of the construction business market. For example, reliable suppliers are more likely to deliver acceptable work on time than are unreliable suppliers, but not always.

Figure 1 shows an example of a problem set. The problem requires contractors to procure sufficient steel on time (ie, before the first half of each project is completed) for the three announced projects with various schedules and deliver the steel to the corresponding locations by negotiating with suppliers. Based on this information and the number of contractors and suppliers currently on the market, suppliers must estimate the steel demand for each season and the bid from the wholesaler and sell to contractors.

\begin{tabular}{|c|c|c|c|c|c|c|c|}
\hline \multicolumn{4}{|c|}{ Year 1} & \multicolumn{4}{|c|}{ Year 2} \\
\hline Season 1 & Season 2 & Season 3 & Season 4 & Season 1 & Season 2 & Season 3 & Season 4 \\
\hline & \multicolumn{6}{|c|}{$\begin{array}{l}\text { Project A, New Taipei City, Xindian } \\
\text { (requiring } 2000 \text { tons of reinforcing steel) }\end{array}$} & \\
\hline & \multicolumn{5}{|c|}{$\begin{array}{l}\text { Project B, Taichung City, Peitun } \\
\text { (requiring } 1500 \text { tons of steel) }\end{array}$} & & \\
\hline & & & \multicolumn{4}{|c|}{$\begin{array}{l}\text { Project C,Tainan City, Rende District } \\
\text { (requiring } 1500 \text { tons of steel) }\end{array}$} & \\
\hline
\end{tabular}

Figure 1: Game set of project duration 


\section{Roles}

The roles in the game include contractors, suppliers and roles without winning objectives, such as wholesalers, bankers and storage space providers. Students are divided into two groups, contractors and suppliers. The administrator or teaching assistant plays the roles without winning objectives. The suppliers are provided with equal initial funds, and they estimate the amount of steel required by the market during each season and bid for the steel for each quarter by considering the number of competitors (ie, suppliers) and buyers (ie, contractors). Once bidding finishes and the amount of steel acquired for each season is established, suppliers post-listed unit prices and wait for contractors to negotiate and buy steel from them.

Contractors are also provided with initial funds and must first plan their procurement schedules according to the project schedules because they must procure all the steel required by a project before the first half of the project is completed. For projects longer than two seasons, contractors can choose to schedule the procurement by concentrating on a particular season or distributing it over several seasons. Contractors then evaluate and select suppliers from the market with whom to negotiate on price, quantity, payment terms, advance payments and delivery options. Payment term options include cash, 30-day check, 45-day check, and 60-day check. Payment period options include on delivery, on completion of milestones, on completion, monthly and biweekly. Advance payment options include 10\%, 15\%, 20\%, 25\% and 30\%. Delivery options include single delivery, multiple deliveries and on-call delivery. Contractors must also distribute the steel among the projects. The evaluate-negotiate-procure-distribute process is repeated each quarter until the final project is completed.

The wholesaler determines the amount of steel awarded to the bidding suppliers for each season based on their bidding prices and intended procurement quantities at the beginning of the game. The wholesaler also collects the leftover steel over purchased by contractors at an average floor price during wholesale bidding. The teaching assistant plays the role of wholesaler and performs other administrative duties, such as auditing the cash flow, including accounts payable and receivable, and awarding penalties.

\section{Process flow}

As shown in Figure 2, the players (students) are divided into suppliers and contractors, with the teaching assistant playing the role of the wholesaler. The number of contractors should exceed the number of suppliers. A ratio of 1:2 is desirable for maintaining the competiveness between suppliers and contractors in a class of 30 students. Increasing the ratio (eg, 1:3) is appropriate for a larger class.

The game consists of three phases: preparation, gameplay and commissioning. During preparation, the teaching assistant sets up the game problem set (ie, the projects to be released to the market) and adjusts the system parameters (eg, the initial funds and free storage space available to each contractor and supplier, and the game pace). Suppliers and contractors must first randomly draw their locations, work quality and schedule performance levels. They must then read the game rules and information on the released projects and the market, such as the number of contractors and suppliers and the highest and lowest wholesale prices.

During gameplay, in addition to the initial amount of steel supplied at the start of the game, suppliers may acquire more steel for each season by placing bids with the wholesaler. The wholesaler announces and distributes steel for each season according to the bidding prices. Whereas suppliers wait for inquiries from contractors, contractors select their preferred suppliers from the market and start negotiating with them. Negotiations may continue for a few cycles until a final agreement is reached. Contractors may allocate the procured steel to projects according to their schedules for each season. 


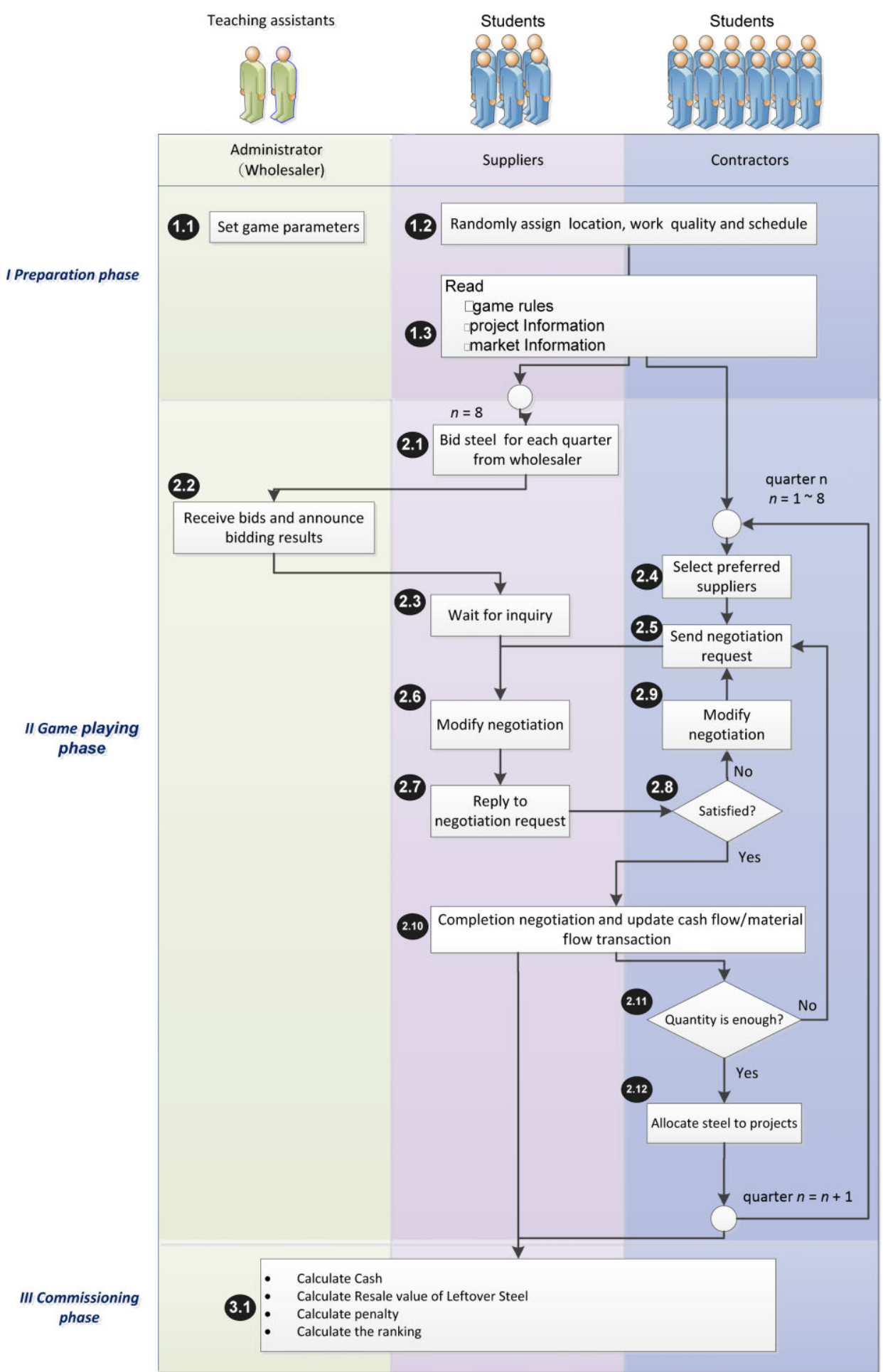

Figure 2: Game flow chart 
During the commissioning process, suppliers and contractors resell their surplus steel and calculate their profits, which are subject to penalties that occur during gameplay. The final rankings of the suppliers and contractors are announced at the end of the game.

Uncertainties and penalties

Three aspects of the game design involve a randomness feature used to mimic the dynamic and uncertain nature of the construction market. The problem set for each game is composed of modularised sub-problems (which differ by project location, size and duration); therefore, the problem set is different for each round of gameplay, even if a player plays twice. A random draw determines each supplier's quality and schedule performance and each contractor's location. Poor quality and late progress penalties are also random, with a trend accounting for the supplier's quality and schedule performance level.

In addition to earning as much revenue and reducing as many costs as possible, players must avoid penalties, which are converted into cash at the end of the game. Penalties include random penalties for poor quality and late progress, and deterministic penalties for excess storage space and the number of negotiations. Contractors and suppliers remain anonymous to prevent alliances among students. Negotiations are also conducted using forms, and no verbal communication is allowed to ensure that negotiations are recorded.

Paper-based and web-based games

Paper-based and web-based versions of the proposed game were implemented. The paper-based game incorporated real props, such as cards and record sheets, to simulate the actual negotiation process in which students made negotiation decisions. Negotiation was facilitated by props instead of face-to-face discussions because, although slightly inconvenient, this is more game-like and may encourage students to participate and prevent cheating.

The web-based game enabled multiplayer online negotiations, in which a contractor could negotiate with multiple suppliers simultaneously. The system enables players to concentrate on procurement and negotiation strategies without bookkeeping distractions (which are included in the paper-based game) by automatically performing bookkeeping tasks (eg, material, storage space and cash flow calculations) for players. However, this requires each player to have access to a networked computer.

Figures 3 and 4 show the implementation of the two game versions, which differed based on the following processes:

Step 1.2 Random assignment. The paper-based games involved the use of dice (Figure 3), and the web-based game implemented computer-generated random numbers.

Step 2.4 Preferred supplier selection. The web-based game enabled contractors to see the quantity of steel held by each supplier in real time (Figure 5). In the paper-based game, the administrator updated and announced the supplier quantities each quarter.

Steps 2.5-2.9 Negotiation. In the paper-based game, the players filled out forms (Figures 3 and 4) and communicated with each other through messengers (the teaching assistant). In the webbased game, players communicated with each other using internet-based forms (Figure 6).

Step 2.11 Allocating steel to projects. In the paper-based game, the administrator only assessed if the contractors procured sufficient steel for the projects scheduled in each season. Contractors could not choose to allocate steel to specific projects. However, in the web-based game, they could allocate steel to specific projects. This feature was useful when, for example, a contractor knew that the amount of steel procured was insufficient for completing two projects scheduled in a particular season and could allocate all of his or her procured steel to a specific project instead of distributing the steel evenly between two projects to reduce penalties and earn a completion bonus. 


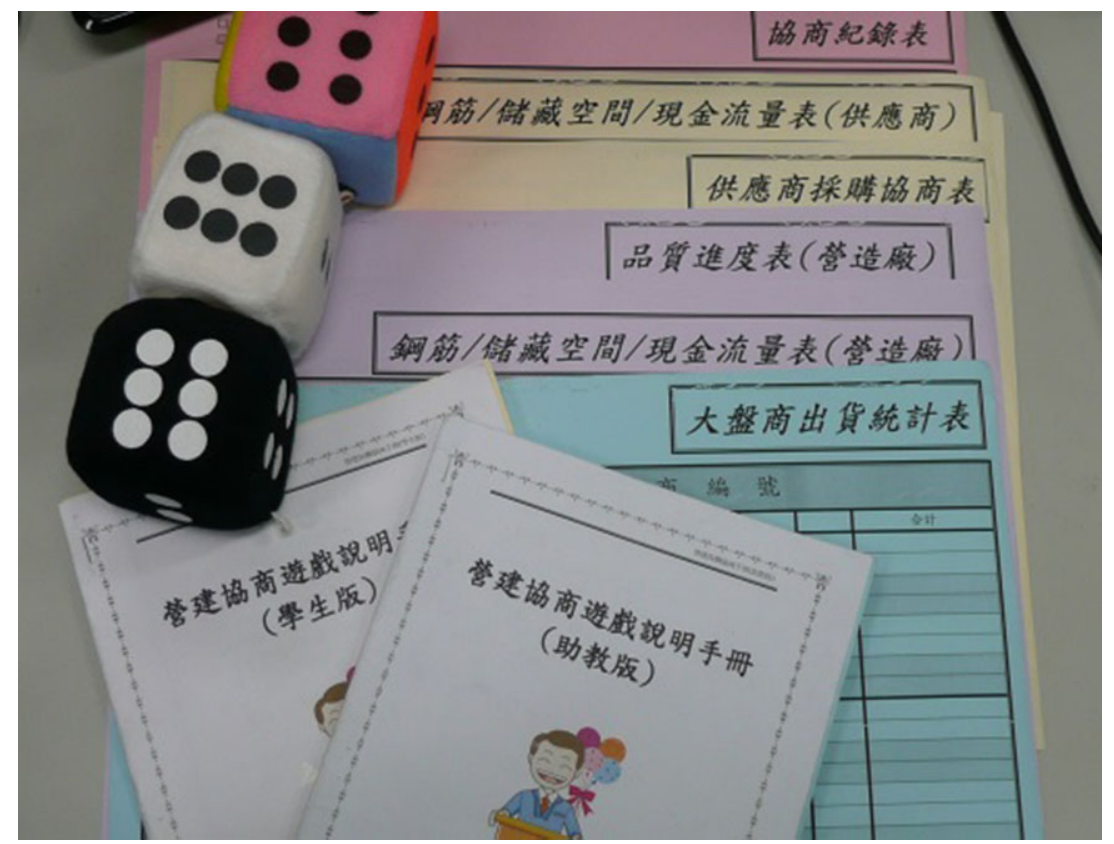

Figure 3: Dice and a variety of forms

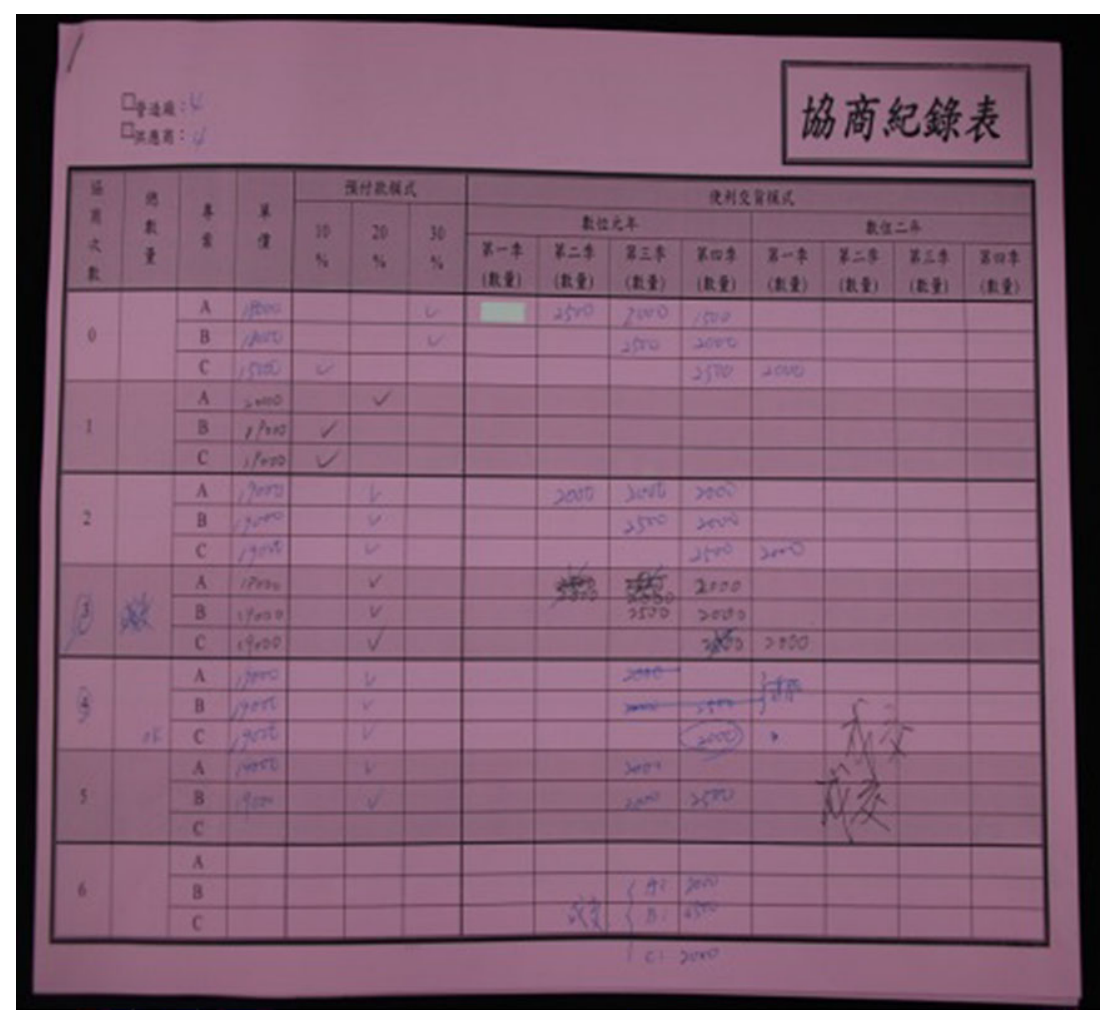

Figure 4: Negotiation records 


\begin{tabular}{cccccc}
\hline Supplier List & \multicolumn{5}{c|}{} \\
Supplier Name & Location & Quality & Delivery & Steel Amount & Steel Price \\
\hline Bill & North Area & Poor & Excellent & 200 & 18,000 \\
Binson & South Area & Moderate & Poor & 381 & 37,649 \\
Candy & North Area & Excellent & Excellent & 3,000 & 19,000 \\
Cindy & North Area & Poor & Moderate & 303 & 33,277 \\
Dzeng & North Area & Poor & Excellent & 5,118 & 28,585 \\
Emily & North Area & Moderate & Excellent & 3,633 & 38,441 \\
Jane & North Area & Moderate & Moderate & 1,488 & 18,839 \\
Jaxon & North Area & Moderate & Moderate & 3,837 & 20,967 \\
John & Central Area & Moderate & Poor & 987 & 34,371 \\
Kager & North Area & Poor & Moderate & 1,950 & 23,000 \\
Nick & Central Area & Excellent & Excellent & 3,175 & 23,708 \\
Ray & North Area & Poor & Excellent & 2,934 & 39,434 \\
Roger & North Area & Poor & Moderate & 5,049 & 19,572 \\
Ruru & North Area & Moderate & Excellent & 5,122 & 37,485 \\
Wayne & North Area & Excellent & Poor & 1,888 & 21,520 \\
William & Central Area & Poor & Moderate & 4,360 & 16,954 \\
& & & & & \\
\hline & & & & & \\
\hline
\end{tabular}

Figure 5: Contractor is browsing the location, quality, schedule, quantity and listed price of suppliers in the market

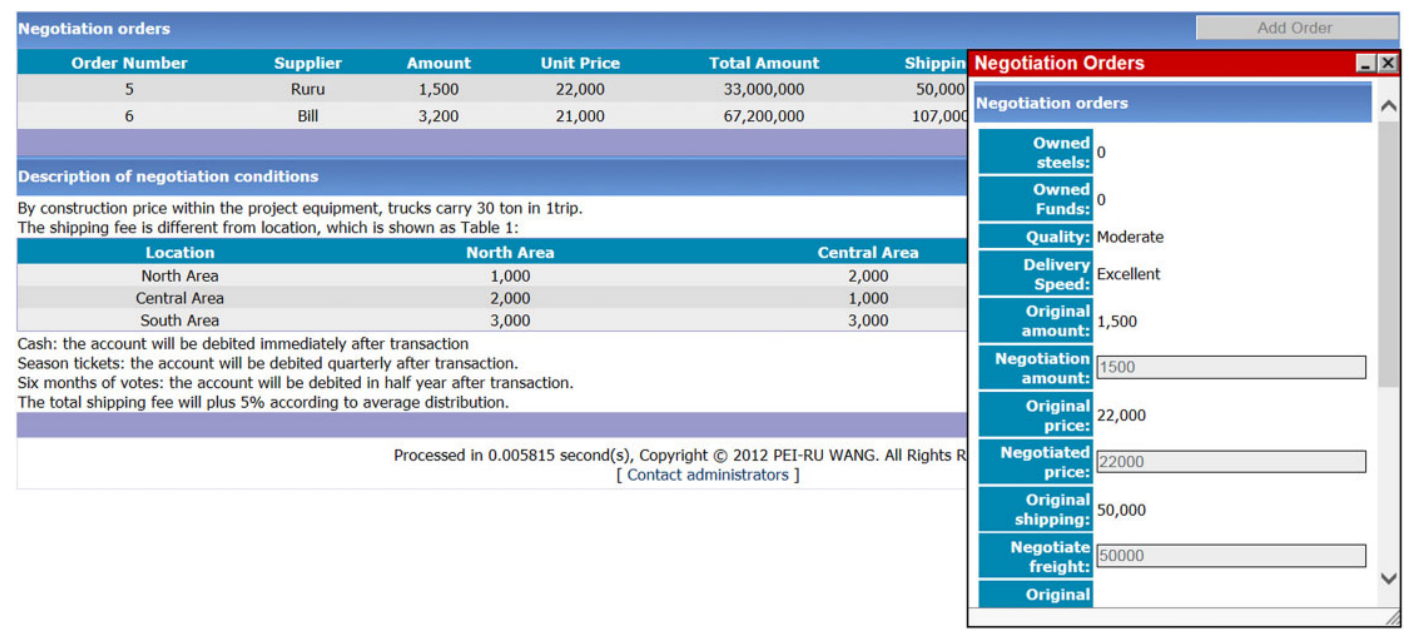

Figure 6: Supplier is replying negotiation form to the selected contractor

Steps 3.1 Commissioning phase. In the paper-based game, players updated their cash flows and material flows, and the administrator calculated the value of the surplus steel and penalties for each player (Figure 3). The system automatically performed the same bookkeeping tasks in the web-based game.

The props used in the paper-based game included three instruction manuals (for students playing contractors and suppliers, and the teaching assistant), three dice and six forms (Figure 3), of which two were for the teaching assistant (wholesaler sale statistics and quality- and schedulelevel forms), one was for the contractor (steel, space and cash flow bookkeeping forms), two were for the supplier (steel, space and cash flow bookkeeping and wholesale bidding forms) and one was for the contractor and supplier (negotiation record forms; Figure 4). 
The web-based system was developed using the Hypertext Preprocessor programming language and MYSQL database (Oracle Corporation, Redwood City, CA, USA). The system included six modules:

1. Market announcement board. This board announces the game rules and the projects to be completed by the contractors.

2. Market statistics board. This board shows the statistics on public player information and market statistics, such as the highest-, lowest- and average-selling price of steel from previous seasons.

3. Player executive control board. This board enables players to view their basic information, the procurement progress for each project, cash flow, material flow and storage space.

4. Negotiation board. This board enables a player to view the suppliers who are available for negotiations, send and reply to negotiation messages, track negotiation histories, and finalise orders.

5. Wholesale bidding board. This board enables suppliers to view the market status (eg, the number of contractors and suppliers and estimated average demand for each supplier) and bidding history (eg, past bid prices and procured quantities) and submit bids.

6. Survey board. This board enables players to complete a survey after playing the game.

\section{Experimental design}

As shown in Table 1, the participants in this study comprised 67 graduate students enrolled in CM courses at National Chiao Tung University, Taiwan, over two fall semesters. The students in each class were divided into three approximately equal groups: a control group, Group A and Group B. We imposed different teaching approaches on the groups: traditional lectures, lectures and the paper-based game, and lectures and the web-based game. Group A played the paper-based game, and Group B played the web-based game. Table 2 shows the basic demographic information of the three groups.

The experiment was conducted using the following procedure (Figure 7). All three groups attended a 2.5-hour lecture and then completed a 0.5-hour pretest exam on construction procurement and negotiation in the same classroom (ie, EB403). The control group was assigned a case study on any subject related to construction procurement and negotiation. They used internet and library searches and interviews to research these case studies, and they had a month to

Table 1: Experimental design

\begin{tabular}{lcccc}
\hline Group & Teaching method & Pretest & Teaching methods & Post-test \\
\hline Control group & $\mathrm{X}_{1}$ & $\mathrm{O}_{1}$ & $\mathrm{X}_{2}$ & $\mathrm{O}_{2}$ \\
Group-A & $\mathrm{X}_{1}$ & $\mathrm{O}_{3}$ & $\mathrm{X}_{3}$ & $\mathrm{O}_{4}$ \\
Group-B & $\mathrm{X}_{1}$ & $\mathrm{O}_{5}$ & $\mathrm{X}_{4}$ & $\mathrm{O}_{6}$ \\
\hline
\end{tabular}

$\mathrm{X}_{1}$, traditional lecture; $\mathrm{X}_{2}$, case project; $\mathrm{X}_{3}$, paper-based game; $\mathrm{X}_{4}$, web-based game.

Table 2: The basic demographic information of the participants

\begin{tabular}{|c|c|c|c|c|c|c|c|c|c|c|}
\hline \multirow[b]{2}{*}{ Group } & \multirow[b]{2}{*}{$\begin{array}{l}\text { Number } \\
\text { of people }\end{array}$} & \multicolumn{2}{|c|}{ Commencement } & \multicolumn{2}{|c|}{$\operatorname{Sex}$} & \multicolumn{2}{|c|}{ Work experience } & \multicolumn{3}{|c|}{ Actual age } \\
\hline & & $\begin{array}{c}\text { Full } \\
2010\end{array}$ & $\begin{array}{l}\text { Full } \\
2011\end{array}$ & Male & Female & $\begin{array}{l}\text { Non- } \\
\text { work }\end{array}$ & Work & $\begin{array}{l}20-30 \\
\text { years old }\end{array}$ & $\begin{array}{l}30-40 \\
\text { years old }\end{array}$ & $\begin{array}{l}\text { Over } 40 \\
\text { years old }\end{array}$ \\
\hline Control group & 22 & 10 & 12 & 17 & 5 & 11 & 11 & 11 & 6 & 5 \\
\hline Group A & 24 & 11 & 13 & 20 & 4 & 12 & 12 & 12 & 8 & 4 \\
\hline Group B & 21 & 10 & 11 & 16 & 5 & 14 & 7 & 14 & 6 & 2 \\
\hline
\end{tabular}




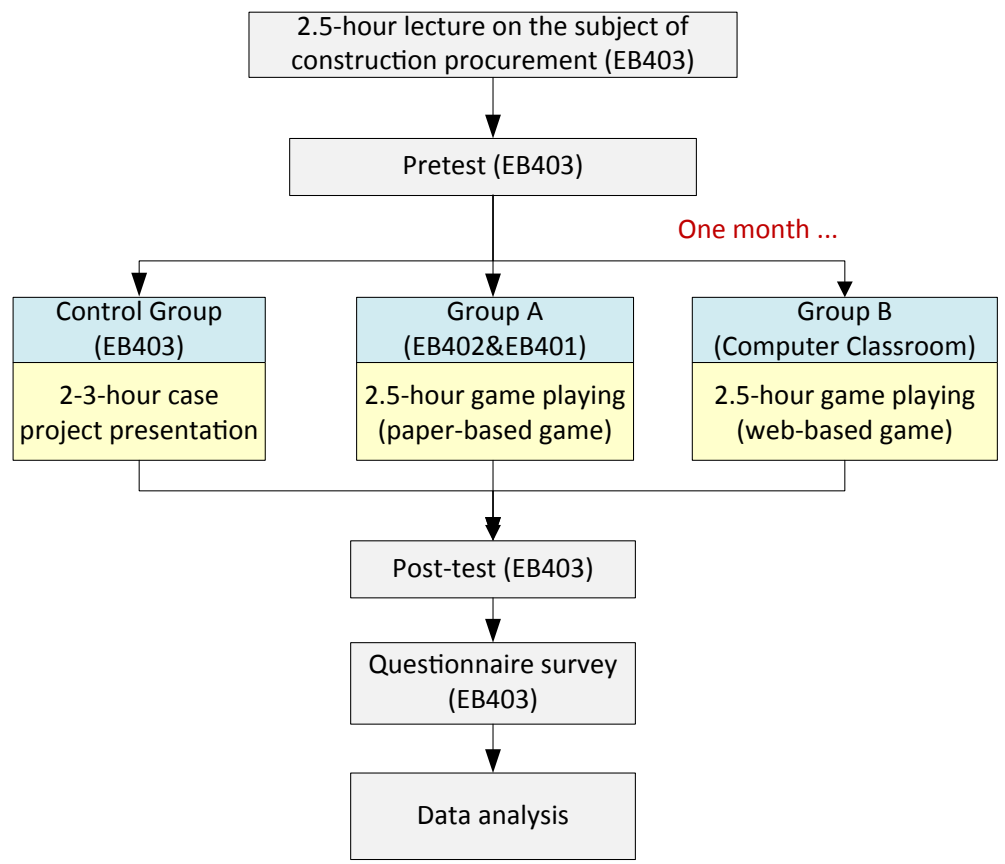

Figure 7: Experiment process

complete their projects. Without receiving any further instruction, after approximately 1 month, each student in the control group presented his or her case to the entire group. The other two groups simultaneously participated in a 2- to 3-hour game played in separate classrooms. All three groups then joined together in the same classroom to complete a post-test, followed by a survey. All three groups completed the same pretest and post-test. The questions in the post-test were different from those in the pretest, but they shared a similar structure and difficulty level.

The purpose of the questionnaire was to measure the learning motivation, satisfaction and effectiveness of the participating students. In addition, it asked students to compare the proposed teaching approach with the traditional approach. The learning motivation questionnaire was modified from that developed by Hsieh et al (2012), and the learning satisfaction and effectiveness questionnaire was modified from that created by Chu et al (2010). Eighteen items addressed the three dimensions, seven items were used to compare the teaching methods by implementing a 5-point Likert scale (5, strongly agree; 4, agree; 3, neither agree nor disagree; 2, disagree; and 1, strongly disagree), and seven items addressed basic participant information. The Cronbach's $\alpha$ values for the four dimensions, including the comparison, were $.846, .831, .854$ and .825 , thus reflecting satisfactory internal consistency reliability. The current study confirmed the construct validity of the questionnaire using factor analysis (Appendix I). Principal components analysis and Varimax were also adopted to verify the meaningfulness and independence of the survey questions. The survey result was analysed using factor analysis (Kaiser-Meyer-Olkin Measure of Sampling Adequacy $(\mathrm{KMO})=.806$, Bartlett's chi-squared test $=426.339)$ and contributed to the four major items with an explanation variance of up to $69.172 \%$.

Experimental results

Figure 8 shows a comparison of the pretest and post-test scores for the three groups by using box plots. The figure shows the mean, median, first and third quartiles, and the maximal and the minimal scores of each group. It also shows the standard deviation for each group and the average 


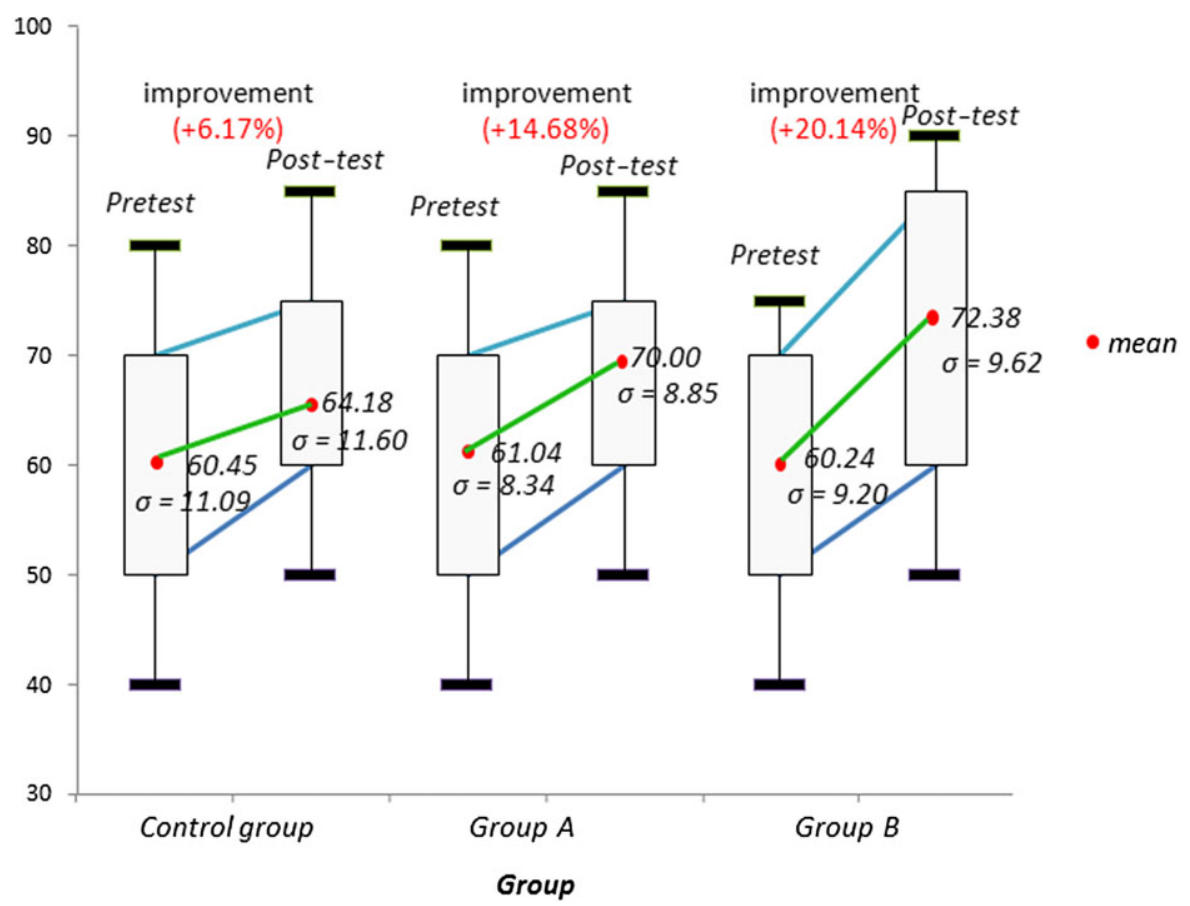

Figure 8: Box plot of pretest-post-test scores for three groups

test score improvement. The web-based gameplayers (Group B) improved the most (20.14\%), and the control group improved the least $(6.17 \%)$. The results indicate that playing the game improved student test scores by $14 \%$ and $20.14 \%$ for Groups A and B respectively. However, the standard deviation for the tests was large, indicating diverse scores. Further analysis of the scores revealed that the improvements in the minimal scores were approximately the same, irrespective of the teaching approach. However, the maximal score produced by Group B improved the most. The results indicate that using different teaching approaches made little difference to students with lower learning abilities, but the web-based game improved the average score and the scores of students with higher learning abilities.

Statistical methods used to determine learning achievements

This study conducted analysis of covariance (ANCOVA) by using participant pretest scores as the covariate to exclude the effect of the pretest on student learning achievements. ANCOVA assumes that the regression coefficients between groups are homogeneous. Based on the non-significant interaction between the independent variable and the test covariate $(F=1.838, p>.05)$, using ANCOVA was appropriate.

Table 3 shows that the variance among the three groups was significant $(F=8.661, p<.05)$ after the effect of the pretest scores on the post-test scores was excluded. In other words, the post-test scores among the groups were significantly different because of the different experimental teaching approaches used. The control group produced an adjusted mean score of 63.40, Group A scored 69.90 and Group B scored 73.31. The significantly higher scores of the experimental groups suggest that the games improved the learning achievements of the construction procurement and negotiation students.

Table 3 also shows that the difference in the Group A test scores between participants with and without work experience was significant $(F=6.670, p<.05)$ after excluding the effect of the 
Table 3: Descriptive data and the ANCOVA result of the post-test

\begin{tabular}{|c|c|c|c|c|c|c|c|}
\hline Variable & Group & $\mathrm{N}$ & Mean & SD & Adjusted & $\begin{array}{l}\text { Standard } \\
\text { error }\end{array}$ & $\mathrm{F}$ \\
\hline \multirow[t]{3}{*}{ Post-test } & Control group & 22 & 64.18 & 11.60 & 63.40 & 1.87 & $8.661^{*}$ \\
\hline & Group A & 24 & 70.00 & 8.85 & 69.90 & 1.79 & \\
\hline & Group B & 21 & 72.38 & 9.62 & 73.31 & 1.92 & \\
\hline \multirow[t]{6}{*}{ Post-test } & Work experience (control group) & 11 & 67.27 & 11.04 & 65.34 & 2.67 & $1.254^{* *}$ \\
\hline & No work experience (control group) & 11 & 59.09 & 11.14 & 61.03 & 2.67 & \\
\hline & Work experience (Group A) & 12 & 74.58 & 8.38 & 73.82 & 2.06 & $6.670^{*}$ \\
\hline & No work experience (Group-A) & 12 & 65.42 & 6.89 & 66.18 & 2.06 & \\
\hline & Work experience (Group B) & 7 & 75.00 & 13.22 & 74.63 & 5.90 & $0.169^{* *}$ \\
\hline & No work experience (Group B) & 14 & 71.94 & 12.26 & 72.01 & 2.41 & \\
\hline
\end{tabular}

${ }^{*} p<0.05 ;{ }^{* *} p>0.05$. ANCOVA, analysis of covariance; SD, standard deviation.

\section{Estimated marginal means of post-test}

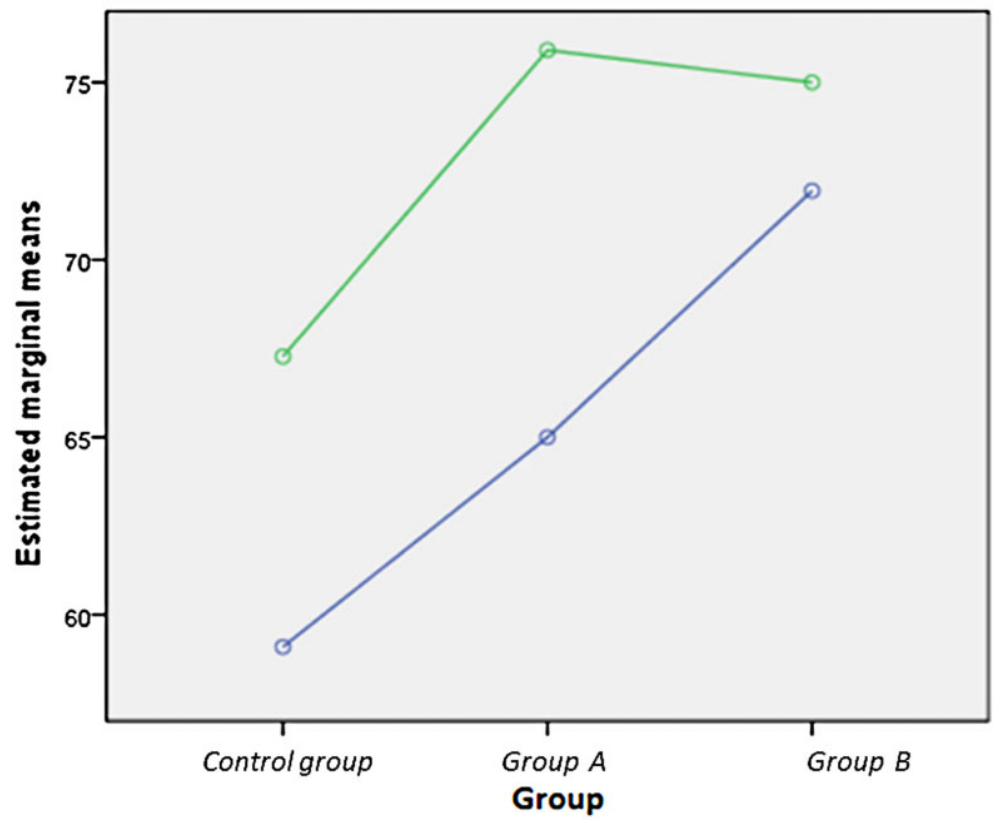

Figure 9: Post-test scores and work experience in three groups. Work experience: —, no; —, yes

pretest scores. Participants with work experience had an adjusted post-test mean of 73.82, whereas those without work experience had an adjusted mean of 66.18 . This result indicates that participants with work experience improved significantly more than those without experience did after playing the paper-based game. This difference was not significant in Group B. Figure 9 shows a comparison of the post-test scores between the participants with and without work experience for the control group, Group A and Group B. It also shows that the difference was much smaller in Group B than in Group A.

Generally, the experimental group scores were higher than the control group scores. This may be because the negotiation activities were intensive and attention demanding and involved a specific winning objective compared with the loosely defined, month-long case study involving a wide 
range of subjects from which to choose. Reports from the control group indicate that the content of the case studies was primarily superficial and was not discussed in depth.

In all three groups, participants with work experience typically produced higher post-test scores than those without work experience. Figure 9 shows that the participants without work experience who played the web-based game produced higher test scores than those who played the paper-based game. However, the participants with work experience who played the paper-based game performed more favourably than those who played the web-based game. This may be because the web-based game uses a computer and requires players to refer to multiple web pages. This may have negatively affected the learning of participants with work experience who were professional students working on construction sites and did not have as much computer experience as full-time students did. These students were more comfortable calculating everything on a single form in the paper-based game than they were when using the web interface. However, calculating the cash and material flows may also have negatively affected the negotiation strategy of the participants without work experience, and the web-based system conducted this tedious work for them.

Satisfaction with and acceptance of the game

Table 4 shows the descriptive statistics on the student responses to the satisfaction and acceptance items for learning with an educational game. The means for all the learning motivation items were greater than 4 , with a Group A mean of 4.3 and a Group B mean of 4.36, indicating that the students agreed that both of the games motivated their learning.

The means for the majority of the learning satisfaction items were greater than 4 , including students' perception of the rules, props or user interface, and difficulty of the game. However, the Group A means for content design and negotiation interaction were 3.87 and 3.83 respectively. Although the Group B means for these items were greater than 4, they were the lowest (4.17 and 4.19) for the learning satisfaction item scores. This indicates that the students were quite satisfied with the concept of using the game as a teaching approach, but playing the game was challenging. This was especially true for the paper-based game, in which students performed numerous tedious calculations. Nevertheless, because the lowest means were greater than 4 , the automatic calculation conducted in the web-based game mitigated this challenge. After the game was over, several participants complained about the tedious cash flow calculations, stating that the calculation errors and time consumed caused them to have insufficient time to focus on negotiation strategies.

All the learning effectiveness means were greater than 4 (Group A, 4.16; Group B, 4.26), indicating that the students believed that both games improved their learning effectiveness. The lowest mean for Group A was 4.01 for "facilitates the understanding of cash and material flows." This can be attributed to the tedious calculations required when updating cash and material flows. Automating the calculation in the web-based game improved the mean for the corresponding item.

When asked to compare the traditional and game-based approaches, Groups A and B agreed that using only traditional lectures or games is inadequate for learning the subject (mean $=4.41-$ 4.62). The students also agreed that integrating games and lectures is necessary for learning the subject and that this integrated approach was significantly more effective than the traditional lecture approach was in improving their learning motivation, satisfaction and effectiveness.

The means for the "overall" items (ie, the final item) in each aspect were also greater than 4 , and these items were generally the highest-scoring items among the aspects. This means that the students agreed that integrating the game with the lecture benefitted overall learning motivation, satisfaction and effectiveness. Group B consistently produced higher means for all items except for Item 3 for learning motivation. However, the difference was only significant for Items 2, 4 and 5 


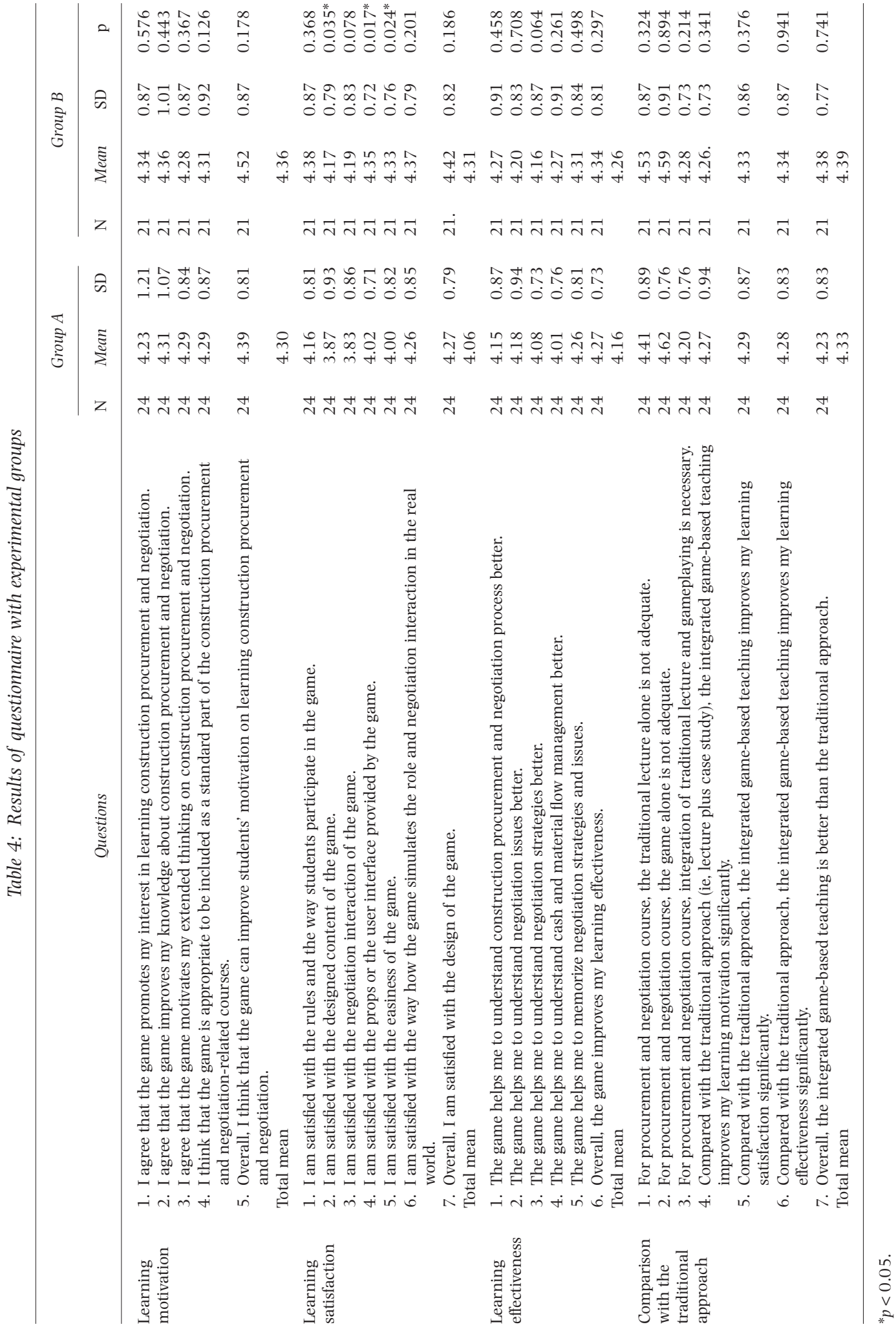


for learning satisfaction (ie, designed content, props and the user interface, easiness of the game). This result indicates that the automation and instantaneous responses enabled by computerisation (such as automatic flow updates, instantaneous market information and simultaneous negotiation with multiple parties) positively affected the students' overall appraisals of the game, particularly in improving satisfaction with the game regarding the designed content, props and the user interface, and easiness.

In cross-examining the results with the two roles, for the contractors, Group B also produced significantly higher means for Items 2,4 and 5 for learning satisfaction with $p$ values of .021, .039 and .027 respectively (data not shown). The result was as expected because the cash flow calculation was the likely most difficult task for contractors, and the computerisation tended to ease this part the most. However, for suppliers, Group B still produced significantly higher means for Items 4 and 5 for learning satisfaction, with $p$ values of .012 and .045 respectively. Based on the after-survey interview, the result might be attributable to the integrated display feature of multiple intermediate negotiations, which makes negotiating with multiple parties easier.

\section{Discussion and conclusion}

In this study, an educational game was developed to supplement traditional lectures on construction procurement and negotiation. Students participated in the game by acting as contractors or suppliers. The contractor's objective was to make the most profit by fulfilling the project procurement requirements through negotiations with suppliers. The supplier's objective was to sell materials through negotiation. The contractors and suppliers were subject to over-storage and negative cash flow penalties as well as randomly determined delivery times and supplier performance.

Based on this framework, we implemented paper-based and web-based versions of the game and conducted an experiment with three groups (ie, a control group; Group A, who played the paper-based game; and Group B, who played the web-based game) to evaluate the game. The results of the experiment indicate the following:

- Playing the paper-based game or web-based game improved student test scores by an average of $14 \%$ and $20.15 \%$ respectively. Playing the games only slightly improved the test scores of students with low learning abilities. However, playing the web-based game improved the test scores of students with high learning abilities much more than the paper-based game did.

- Generally, students with work experience produced higher scores than students without work experience for all the teaching approaches used. Of the students without work experience, those who played the web-based game exhibited the highest post-test scores. However, of the students with work experience, those who played the paper-based game had the highest scores. This may be because students with work experience are less familiar with using computers than those without experience are, and manipulating several web pages may interfere with their learning. In the paper-based game, performing calculations inhibited the learning of students without work experience, but not the learning of students with work experience. The students with work experience appreciated that calculations were integrated into a single paper form.

- The means for the "overall" items in each aspect were greater than 4 , and the means of these items were generally the highest within an aspect. This suggests that the students agreed that integrating the game with the lectures benefitted overall learning motivation, satisfaction and effectiveness. Group B consistently produced higher means for most items, indicating that the automation and instantaneous responses enabled by computerisation (such as automatic flow updates, instantaneous market information and simultaneous negotiation with multiple parties) positively affected the students' overall appraisals of the game, especially in improving the satisfaction of the game in terms of designed content, props or the user interface, and easiness. 
- The means for most of the items were greater than 4 , indicating that the students agreed that the proposed games benefitted their learning motivation, satisfaction and effectiveness and that integrating the game and lectures was more effective than only attending lectures. However, the means for the content design and negotiation interaction items in the learning satisfaction aspect for Group A were 3.87 and 3.83 respectively. Although the means for the same items for Group B were greater than 4 , they were the items with the lowest means in this aspect. This indicates that the students were quite satisfied that the game was introduced as a component of the teaching approach, but playing the game was challenging, mostly because of the complex cash flow calculations.

Although the web-based game produced higher survey scores than the paper-based game did, students with work experience achieved higher test scores than those without work experience did. The paper-based game shares more similarities with current professional practices than the Web version does, which corresponds to the experience of the students with work experience. Nevertheless, playing the paper-based game involves additional effort to be exerted by both the administrator and the player and also decreases the satisfaction level of students. Students with work experience produced higher scores than those without work experience did. This suggests that the test favoured students with work experience and that hands-on experience helped students learn construction procurement and negotiation. Future studies should focus on simplifying the web-based game interface to improve its usability for students with minimal computer experience. Studies should also investigate the differences between game winners and losers based on their negotiation strategies and strategy transition patterns.

\section{Acknowledgement}

This study was supported by the National Science Council of Taiwan under grant numbers NSC97-2511-S-009-005-MY2 and NSC 100-2511-S-145-001.

\section{References}

AbouRizk, S. (1992). A stochastic bidding game for construction management. Proceedings of second Canadian conference on computing in civil engineering (pp 576-587). Ottawa, Ontario: CSCE.

Alavi, M., Yoo, Y. \& Vogel, D. R. (1997). Using information technology to add value to management education. Academy of Management Journal, 40, 6, 1310-1333.

Brown, J. S. \& Duguid, P. (1993). Stolen knowledge. Educational Technology, 33, 3, 10-15.

Cagiltay, N. E. (2007). Teaching software engineering by means of computer-game development: challenges and opportunities. British Journal of Educational Technology, 38, 3, 405-415.

Chang, Y. C., Peng, H. Y. \& Chao, H. C. (2010). Examining the effects of learning motivation and of course design in an instructional simulation game. Interactive Learning Environments, 18, 4, 319-339.

Chou, S. W. \& Liu, C. H. (2005). Learning effectiveness in a Web-Based virtual learning environment: a learner control perspective. Journal of Computer Assisted Learning, 21, 65-76.

Chu, H. C., Hwang, G. J., Tsai, C. C. \& Tseng, J. C. R. (2010). A two-tier test approach to developing locationaware mobile learning system for natural science course. Computers \& Education, 55, 4, 1618-1627.

Connolly, T. M., Stansfield, M. \& Hainey, T. (2007). An application of games-based learning within software engineering. British Journal of Educational Technology, 38, 3, 416-428.

Dudziak, W. \& Hendrickson, C. (1988). Simulation game for contract negotiations. Journal of Management in Engineering, 4, 2, 113-121.

Dzeng, R. J. \& Lin, Y. C. (2004). Intelligent agents for supporting construction procurement negotiation. Expert Systems with Applications, 27, 1, 107-119.

Dzeng, R. J. \& Lin, Y. C. (2005). Searching for better negotiation agreement based on genetic algorithm. Journal of Computer-Aided Civil and Infrastructure Engineering, 20, 4, 280-293.

Ebner, M. \& Holzinger, A. (2007). Successful implementation of user-centered game based learning in higher education: an example from civil engineering. Computers \& Education, 49, 3, 873-890.

Erdem, M. (2009). Effects of learning style profile of team on quality of materials developed in collaborative learning processes. Active Learning in Higher Education, 10, 2, 154-171.

Fasli, M. \& Michalakopoulos, M. (2006). Interactive game based learning. Association for learning Technology. Online Newsletter. Issue 6. Retrieved October 15, 2014. from http://archive.alt.ac.uk/alt.newsweaver .co.uk/newsweaver.co.uk/alt/e_article00067880964e4.html?x=b11,0,w. 
Halpin, D. \& Woodhead, R. W. (1973). Constructo - A heuristic game for construction management. Champaign, IL: University of Illinois Press.

Hao, Y., Hong, J. C., Jong, J. T., Hwang, M. Y., Su, C. Y. \& Yang, J. S. (2010). Non-native Chinese language learners' attitudes towards online vision-based motion games. British Journal of Educational Technology, $41,6,1043-1053$.

Hsieh, T.-C., Wang, T.-I., Su, C.-Y. \& Lee, M.-C. (2012). A fuzzy logic-based personalized learning system for supporting adaptive English learning. Educational Technology \& Society, 15, 1, 273-288.

Huang, W. H., Huang, W. Y. \& Tschopp, J. (2010). Sustaining iterative game playing processes in DGBL: the relationship between motivational processing and outcome processing. Computers $\mathcal{E}$ Education, 55, 2, 789-797.

Ke, F. (2008). Computer games application within alternative classroom goal structures: cognitive, metacognitive, and affective evaluation. Educational Technology Research and Development, 56, 5, 539-556.

Kiili, K. (2007). Foundation for problem-based gaming. British Journal of Educational Technology, 38, 3, 394-404.

Kim, B., Park, H. \& Baek, Y. (2009). Not just fun, but serious strategy: using meta cognitive strategies in game-based learning. Computers and Education, 52, 4, 800-810.

Liu, T. Y. \& Chu, Y. L. (2010). Using ubiquitous games in an English listening and speaking course: impact on learning outcomes and motivation. Computers \& Education, 55, 2, 630-643.

McKeachie, W. J., Printrich, P. R., Lin, Y. \& Smith, D. (1987). Teaching and learning in the college classroom: $a$ review of the research literature (pp 314-999). Ann Arbor, MI: National Center for Research to Improve Postsecondary Teaching and Learning (NCRIPTAL),The University of Michigan, ERIC ED.

Nassar, K. (2002). Simulation gaming in construction: ER, the Equipment Replacement game. Journal of Construction Education, 7, 1, 16-30. 15.

Papastergiou, M. (2009). Digital game-based learning in high school computer science education: impact on educational effectiveness and student motivation. Computers \& Education, 52, 1, 1-12.

Piccoli, G., Ahmad, R. \& Ives, B. (2001). Web-based virtual learning environments: a research framework and a preliminary assessment of effectiveness in basic IT skill training. MISQuarterly, 25, 4, 401-426.

Sacks, R., Esquenazi, A. \& Goldin, M. (2007). LEAPCON: simulation of lean construction of high-rise apartment buildings. Journal of Construction Engineering and Management, 133, 7, 529-539.

Shaffer, D. W., Squire, K., Halverson, R. \& Gee, J. P. (2008). Video games and the future of learning. Phi Delta Kappan, 87, 02, 104-111.

Stottler, R. H. \& Vinkavich, M. (2000). Tactical action officer intelligent tutoring system (TAO ITS). In proceedings of the industry/interservice. Training, Simulation \& Education Conference (I/ITSEC). Retrieved October 15, 2014, from http://ntsa.metapress.com/app/home/contribution.asp?referrer=parent\&backto =issue,126,152; journal,14,46;linkingpublicationresults, 1:113340,1

Tommelein, I. D., Riley, D. R. \& Howell, G. A. (1999). Parade game: impact of work flow variability on trade performance. Journal of Construction Engineering and Management, 125, 5, 304-310.

Tüzün, H., Yılmaz-Soylu, M., Karakus, T., Inal, Y. \& Kızllkaya, G. (2009). The effects of computer games on primary school students' achievement and motivation in geography learning. Computers $\mathcal{E}$ Education, 52, $1,68-77$.

Van Eck, R. \& Dempsey, J. (2002). The effect of competition and contextualized advisement on the transfer of mathematics skills in a computer-based instructional simulation game. Educational Technology Research and Development, 50, 3, 23-41.

Wang, L. C. \& Chen, M. P. (2010). The effects of game strategy and preference-matching on flow experience and programming performance in game-based learning. Innovations in Education and Teaching International, 47, 1, 39-52.

Wigfield, A. \& Eccles, J. S. (2000). Expectancy-value theory of achievement motivation. Contemporary Educational Psychology, 25, 68-81.

Yien, J. M., Hung, C. M., Hwang, G. J. \& Lin, Y. C. (2011). A game-based learning approach to improving students' learning achievements in a nutrition course. Turkish Online Journal of Educational Technology, $10,2,1-10$. 


\section{Appendix I}

Table A1: Factor analysis table $(n=25)$

\begin{tabular}{|c|c|c|c|c|}
\hline Learning motivation (Cronbach's $\alpha=.846$ ) & $\begin{array}{l}\text { Extraction } \\
\text { value }\end{array}$ & $\begin{array}{l}\text { Factor } \\
\text { loading }\end{array}$ & Eigenvalue & $\begin{array}{l}\text { Explanation } \\
\text { variance (\%) }\end{array}$ \\
\hline $\begin{array}{l}\text { 1. I agree that the game promotes my interest in learning } \\
\text { construction procurement and negotiation. }\end{array}$ & .745 & .831 & 2.304 & 17.460 \\
\hline $\begin{array}{l}\text { 2. I agree that the game improves my knowledge about } \\
\text { construction procurement and negotiation. }\end{array}$ & .682 & .825 & & \\
\hline $\begin{array}{l}\text { 3. I agree that the game motivate my extended thinking on } \\
\text { construction procurement and negotiation. }\end{array}$ & .706 & .786 & & \\
\hline $\begin{array}{l}\text { 4. I think that the game is appropriate to be included as a } \\
\text { standard part of the construction procurement and } \\
\text { negotiation-related courses. }\end{array}$ & .589 & .716 & & \\
\hline $\begin{array}{l}\text { 5. Overall, I think that the game can improve students' } \\
\text { motivation on learning construction procurement and } \\
\text { negotiation. }\end{array}$ & .632 & .748 & & \\
\hline
\end{tabular}

Learning satisfaction (Cronbach's $\alpha=.831$ )

1. I am satisfied with the rules and the way students

$\begin{array}{llll}.727 & .843 & 3.143 \quad 18.168\end{array}$
participate in the game.

2. I am satisfied with the designed content of the game.

3. I am satisfied with the negotiation interaction of the

$.741 \quad .688$
game.

4. I am satisfied with the props or the user interface provided by the game.

5. I am satisfied with the easiness of the game.

$.682 \quad .640$

6. I am satisfied with the way how the game simulates the role and negotiation interaction in the real world.

7. Overall, I am satisfied with the design of the game.

$.747 \quad .774$

$.711 \quad .762$

$.433 \quad .625$

Learning effectiveness (Cronbach's $\alpha=.854$ )

1. The game helps me to understand construction

$.750 \quad .843 \quad 2.174$

16.395 procurement and negotiation process better.

2. The game helps me to understand negotiation issues better.

$\begin{array}{llll}\text { 3. The game helps me to understand negotiation strategies } & .748 & .849\end{array}$ better.

4. The game helps me to understand cash and material $.747 \quad .830$ flow management better.

$\begin{array}{llll}\text { 5. The game helps me to memorize negotiation strategies } & .540 & .568\end{array}$ and issues.

6. Overall, the game improves my learning effectiveness. 
Table A1: Continued

Comparison with the traditional approach (Cronbach's $\alpha=.825$ )

Extraction Factor Explanation

1. For procurement and negotiation course, the traditional value loading Eigenvalue variance (\%) lecture alone is not adequate.

$\begin{array}{llll}.768 & .712 & 2.304 & 17.149\end{array}$

$\begin{array}{lll}2 \text {. For procurement and negotiation course, the game alone } & .746 & .708\end{array}$ is not adequate.

3. For procurement and negotiation course, integration of $\quad \begin{array}{lll}.724 & .689\end{array}$ traditional lecture and gameplaying is necessary.

4. Compared with the traditional approach (ie, lecture plus $\quad .681 \quad .656$ case study), the integrated game-based teaching improves my learning motivation significantly.

5. Compared with the traditional approach, the integrated game-based teaching improves my learning satisfaction significantly.

6. Compared with the traditional approach, the integrated game-based teaching improves my learning effectiveness significantly.

7. Overall, the integrated game-based teaching is better than the traditional approach.

$.666 \quad .634$

$.768 \quad .751$

$.682 \quad .612$ 